\title{
Undifferentiated Ovarian Sarcoma
}

National Cancer Institute

\section{Source}

National Cancer Institute. Undifferentiated Ovarian Sarcoma. NCI Thesaurus. Code C40066.

An aggressive high grade sarcoma that arises from the ovary. It is characterized by the presence of marked pleomorphism and nuclear atypia in the neoplastic mesenchymal cells. The prognosis is poor. 